\title{
PAYMENT FOR ENVIRONMENTAL SERVICES: ALLEVIATING THE CONFLICT OF PARKS VERSUS PEOPLE
}

\author{
Silveira-Junior WJ ${ }^{1} *$, Salvio GMM${ }^{2}$, Moura $\mathrm{AS}^{1}$, Souza CR $^{1} \&$ Fontes MAL $^{1}$ \\ ${ }^{1}$ Forest Sciences Department, Federal University of Lavras, Cx. P. 3037, Lavras, MG 37200-000, Brazil \\ ${ }^{2}$ Núcleo de Ciências Ambientais, Instituto Federal do Sudeste de Minas - Campus Barbacena, Cx. P. 992, Barbacena, \\ 36205-018, MG 37200-000, Brazil \\ *jjjuniorjf@hotmail.com
}

Submitted October 2018; accepted March 2019

\begin{abstract}
The "parks versus people" conflict is a result of the establishment of protected areas (PAs) that often restrict access to biological resources by the human population, mainly in developing countries. Payment for environmental services (PES) is one of the several strategies that have been developed and implemented in order to mitigate this conflict. This study aimed to evaluate whether PES could smooth the "parks and people" conflict through the analysis of five case studies from different regions and social-environmental contexts. The results have shown that PES may contribute effectively towards conflict resolution, although it was not the main objective. However, the PES results differed between cases due to attributes such as local environmental conditions, local activities and involvement capacity of both the population and local government. Some characteristics must be considered in order to have efficient results, both in biodiversity and environmental services conservation, and in the development of populations involved towards maintaining PES continuity. It is necessary to consider PES joint strategies to improve the process efficiency from diagnoses to decisionmaking.
\end{abstract}

Keywords: Nature conservation, national park, socio-environmental conflict, protected areas, ecosystem services

\section{INTRODUCTION}

The conflict between biodiversity conservation and the indigenous human population wellbeing, known as "parks versus people", is a form of conflict, which began with the Yellowstone National Park, USA creation in 1872 . The fortress conservation model was inaugurated by the establishment of protected areas (PAs) through laws and decrees (Brockington 2002, Adams et al. 2004, Mcshane et al. 2011). This conservation strategy restricts population access to the natural resources of the sites that they historically inhabited through their preservation. This is considered the main cause of conflict that promotes social exclusion, denial of ancestral territorial rights and the consequent population impoverishment (Brockington et al. 2006, Dpourcq et al. 2017).

The constant presence of conflicts in these areas are not be considered negative, since it allows the construction of a unique decision in the face of divergent and opposing positions, and thus may drive important changes (Simmel 1986). Many strategies have been established in order to smooth these conflicts such as: i) the creation of more inclusive PAs, proposed in the World Congress of National Parks held in Bali, Indonesia (1982) and Caracas, Venezuela (1992) (Naughton-Treves 2005), ii) the recognition by the International Union for Conservation of Nature (IUCN) of the different global PAs typologies, organised into six categories related to the level of restriction or possibility in natural resources use (Ia, Ib, II, III, IV, V, VI) (IUCN 1994), and iii) the construction of Integrated Conservation and Development Project (ICDPs) that has as objective to link the local population development to biodiversity conservation (Alpert 1996, Bauch 2014).

The payments for ecosystem or environmental services (PES) are defined as a voluntary transaction between a buyer of the service provided by nature and its provider, which occurs effectively if the ecosystem service provider ensures its provision (Wunder 2015). The PES has been indicated as an effective strategy to smooth the "parks versus people" conflict, since 
it can contribute towards PES maintenance and at the same time generate benefits to the human population involved, including them in the conservation process and relieving their poverty (Clements \& Milner-Gulland 2014).

However, some aspects of the PES requires greater attention because they can influence the design, and consequently result in excessive focus on alleviating the poverty of the provisor population, that may draw attention away from environmental services (Wunder 2008). Overfocusing on economic efficiency can compromise and neglect important issues, such as the procedural fairness and equitable distribution of project outcomes, involvement of national and local public authorities, non-governmental organisations (NGOs), local communities and companies, characteristics of buyers and source of resources used in the purchase of government and private initiatives, amounts paid and opportunity costs, and the valuation of the knowledge of communities on the environmental service provided (Engel et al. 2008, Fisher et al. 2010, Pascual et al. 2014, Chan et al. 2017).

In this study, five empirical studies on PAs in four continents (Asia, Africa, Central and South America) were evaluated in order to verify whether PES can contribute to smoothing the "parks versus people" conflict, and how the experiences may meet both the demands of environmental services and populations involved. The conflicts were initially identified, and the PES project evaluated the bodies involved, the provided environmental services, the values and their origin, the fauna or flora species that were benefited, the populations involved, the factors that have contributed to PES success or failure, and how these factors are related to other strategies used globally to smooth the "parks versus people" conflict.

\section{MATERIALS AND METHODS}

\section{Data collection and analysis}

This study consisted of identifying and analysing PES initiatives developed in PAs or in their surrounding areas that presented "parks versus people" conflicts. The study was divided into two distinct stages. In the first, a survey was carried out on the platforms of Google Scholar, Web of Science and Scopus, using the key words, "payments for environmental services", "protected areas" and "social-environmental conflicts". Priority was given to studies in which PAs fit into IUCN categories (Ia, Ib and II) that are associated with frequent conflicts (IUCN 1994). Five cases of PES were selected, directly related to PAs or to their surroundings (Figure $1)$.

In the second stage, two questions guided the study: i) What factors were preponderant to the success or failure of related PES initiatives? ii) What is the relationship between PES and other strategies that aim to conserve biodiversity and environmental services, and to smooth the conflicts of "parks versus people"? To answer the first question, four aspects were considered: the amounts paid to the populations involved and the opportunity costs to join PES, the valorisation

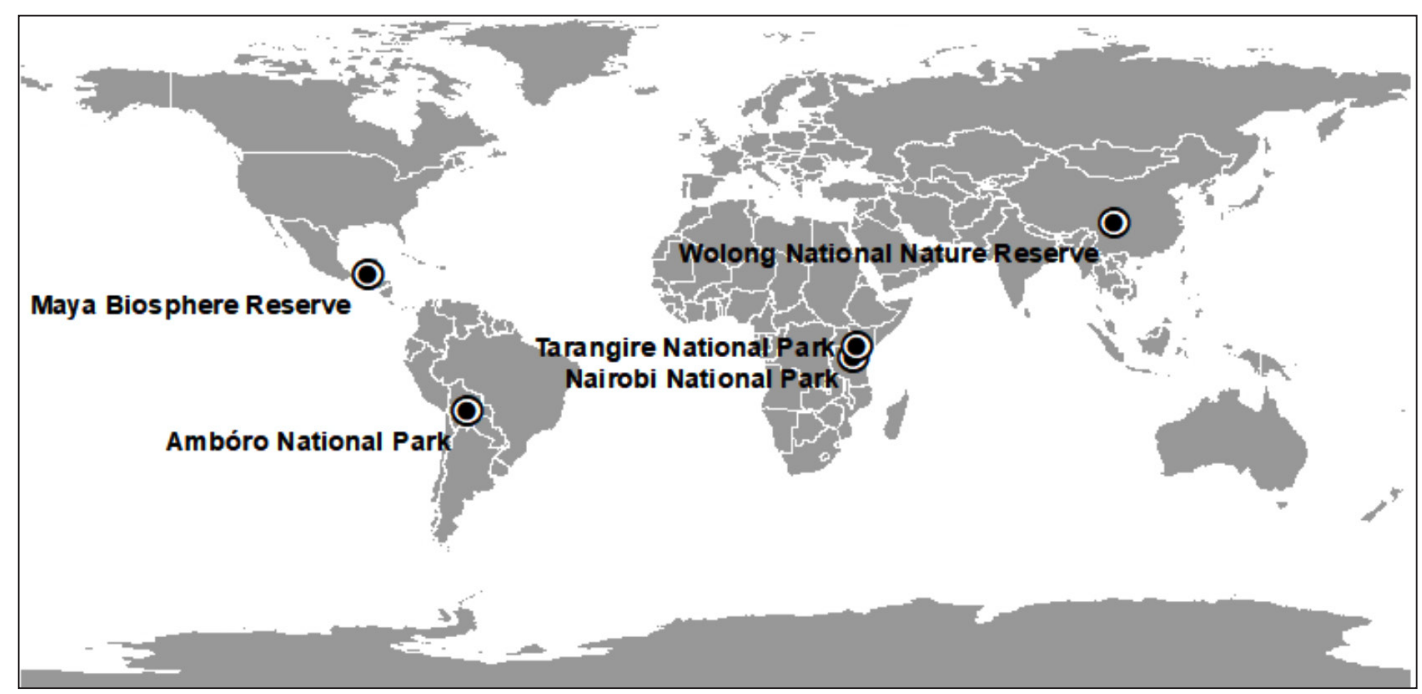

Figure 1 Localisation of the protected areas considered in this study 
of the knowledge of populations involved, the sociopolitical organisation and the participation experience in local populations, the existence of a promising market related to environmental services, and the resources for PES funding. To answer the second question, how PES can work to compensate the failures of PA policy strategies of the Integrated Conservation and Development Projects (ICDPs), were analysed.

\section{Case studies}

The Wolong National Nature Reserve in China (category Ia-IUCN) was founded in 1963 and expanded in 1975, currently covering about $2,000 \mathrm{~km}^{2}$. It houses a great biological diversity, including $10 \%$ of the entire wild giant panda population (Ailuropoda melanoleuca) in the world (Schaller et al. 1985). About 9900 residents of 2200 households reside inside the reserve or immediately outside (Tuanmu et al. 2016). Before PES establishment, the agriculture was the main economic activity, and wood was the main domestic energy source, which contributed a strong pressure on the reserve (Liu et al. 2001, He et al. 2009). In 1998, the Natural Forest Conservation Program (NFCP) established PES in China, aiming to increase the quality of the giant panda's habitat. Based on the fact that the Panda's main food source is bamboo, which needs a canopy cover, the PES aimed to reduce deforestation and to increase the reserve's forest cover. In order to achieve it, payments were propoesed to local families as a compensation for switching timber extraction to forest conservation. Both households and the government are responsible for monitoring and reporting illegal logging in protected forest plots (Tuanmu et al. 2016).

Approximately one-third of the total NFCP monitoring area (approximately 400 of $1,205 \mathrm{~km}^{2}$ ) was allocated to approximately 250 families in Wolong and Gengda, who received an annual payment of about USD110 (8\% of annual family income in the two municipalities in 2001). The families of Sanjiang received half the amount paid to the families of Wolong and Gengda, due to being outside the reserve. The remaining area was monitored by the local government. As a result, there was an improvement in forest cover, contrary to the trend of habitat loss and degradation observed between the years 1960 and 2001. Thus, the reserve experienced a general improvement in panda habitat, which increased by $3.4 \%$ (from 686 to $709 \mathrm{~km}^{2}$ ) between the years 2001 and 2007. The increased income from PES enabled people to consume electricity, which consequently favored less use of forests wood (Tuanmu et al. 2016).

The Maya Biosphere Reserve in Guatemala (category IV-IUCN) was established in 1990 with an area of $21602.04 \mathrm{~km}^{2}$, consisting of archaeological sites, areas of multiple use occupied by human population with wood extraction as their main source of income, and central areas that shelter more restricted PAs. In multiple-use areas, isolated populations of the endangered Meleagris ocellata bird can be found, with their conservation status directly linked to the pressure of uncontrolled subsistence hunting (Baur et al. 2012). The Guatemala's government, through the National Council of Protected Areas (NCPA,) and in partnership with resident populations, developed a project called "Pavo". The project aims the conservations of these birds, associated to living quality improvement of local human populations. The project is based on a sport hunting model in which rural dwellers, through concessions, are mainly responsible for field operations, such as inspection activities, tourist guide work and annual bird population census. In exchange, the population receives a percentage of the income obtained from the sport hunting activity. The funding for the residents' remuneration is obtained by predefined charges to hunter tourists, i.e., the amount for the first slaughtered bird varies between USD1,250 and 1,450 , the second USD700 and the third USD500. The income obtained from protecting the first slaughtered bird is directed to the project, $70 \%$ of the second and $100 \%$ of the third stay with the residents (Baur et al. 2012).

Within each participating concession, the project designates an area of occurrence of the M. ocellata from 25000 to 30000 ha where the activities are carried out. Such management areas are not physically delimited but are indicated on maps within the hunting management region, in plans provided by NCPA audit body, and in public announcements published within participating communities. The management areas are designated based on two criterias, bird population status and vehicular access. Due to hunting pressure, the population density of M. ocellata is directly correlated to the distance from human settlements, which is smaller 
where human activities are concentrated, thus the management areas are located far from villages (Baur et al. 2012). PES establishment has dramatically decreased uncontrolled subsistence hunting, and resulted in stabilisation of the species population (Baur et al. 2012). The two main contributing factors were, the project financial viability, favored by the specialised market for hunting $M$. ocellata, which contributed towards payment to the residents, equivalent to almost two weeks of wages; and the organisation and search for improvement in the quality of services by local residents, mainly due to extensive experience in working with forest concession systems, and the historical economic dependence on the extraction of non-wood forest products.

The Tarangire National Park in Tanzania (category II-IUCN) was founded in 1970, covering about 2,850 $\mathrm{km}^{2}$. The objective of the PES program is to allow wildlife access to the Simanjiro plains located in areas adjacent to the park, and thus encourage tourism and sport hunting that may generate income for tourism companies for the government through collecting fees and taxes, and for the local population through services linked to hunting and tourism. To this aim, the tour operators remunerate members of the Sukuro, Emboreet and Terrat tribes through an annual payment of approximately USD4,500 per tribe, in exchange for the removal of agricultural cultivation and/or the permanent settlements in areas under concession. The agreement also allows for continued seasonal grazing of livestock, as both parties have agreed that this use does not conflict with wildlife conservation objectives. The population is still committed to avoiding activities such as wood burning for coal production and unlicensed hunting in concession areas. In addition, the population also assume responsibility for supervision and custody of the area. The Wildlife Conservation Society contributes by providing wages and equipment to four village members, who act as enforcement agents and receive approximately USD300 in addition to monthly expenses (Nelson et al. 2010).

The Nairobi National Park in Quenia (category II- IUCN) was founded in 1946 and has $114 \mathrm{~km}^{2}$ of area. This plain is part of the pastoral ecosystem known as Kitengela, considered very important for the grazing migratory wildlife. However, due to increasing urban expansion and agropastoral development, the fauna that migrates seasonally to the park areas faced barriers by property fences. The program aims to reduce the barriers between the conservationist and the rural producers associated to the park area by removal of fences from rural properties, and thus allowing the seasonal migration of fauna and the maintenance of economic activities in rural properties. For this purpose, it has been proposed a payment of USD10 $\mathrm{ha}^{-1}$ year $^{-1}$ to landowners (Leeuw et al. 2014).

However, due to the heterogeneity of the region in attributes such as size (small properties and large latifundia) and geographic location (near or far from roads and rivers), characterising them as more fertile and productive, there are different values in the real estate market. For example, the areas closest to the rivers in the ecosystem have a greater value, reaching between USD9,000-12,000 $\mathrm{ha}^{-1}$ in 2008. Therefore, the value offered by the PES was not enough to attract all the owners in the region. Those who accepted the proposal have glimpsed an opportunity to obtain secure reliable financial resources for investing in their children's education, thus using them to conclude payments for the fees required by schools (Leeuw et al. 2014).

The Amboró National Park in Bolivia (category II-IUCN) was founded in 1984, covering an area of 636000 ha and located in the region of Codo de los Andes, where the western mountain range oscillates towards the south, providing different climates and physiognomies to the park. The Park also participates significantly in the protection of springs that supply nine downstream municipalities, in which $80 \%$ of water use is concentrated for agriculture (irrigation). This use is controlled by dam construction and user fees payments (low or zero). However, there is recurrent shortage in drought periods, which hinders the agricultural vegetables production ( 2 to 3 harvests year-1). The main conflict is land invasion by migrant populations, trying to expand their properties by forest deforestation. There are two motivating factors for the invasion, i.e., the fact that most landowners have buy-andsell contracts and not government land titles, and the incentives from local political leaders and syndicate leaders (Asquith et al. 2008).

In 2003, in order to protect the Ambóro National Park and its surrounding areas, the Natura Bolivia Foundation developed a PES of hydrographic basins, where the resources were 
funded by Pampa Grande municipality and US Fish and Wildlife Service. The payments are not made in cash, but in beehives and technical assistance to implement beekeeping activities in the forest areas. The cost is accounted for in the form of USD3 (cost of a beehive) per 10 ha of preserved forest, plus assistance in beekeeping activities (i.e, hired technicians). The farmers reported that they prefer this payment as they have added value to the future, which would not happen if they received money that may not result in benefits if indiscriminately use. Other farmers who do not have aptitude for apiculture may choose to receive fruit tree seedlings or barbed wire (to surround and demarcate their lands) (Asquith et al. 2008).

The observations have shown that many thrive in beekeeping activities. and others that do not have success end up selling their hives. Those who prosper can earn up to USD16.66 ha-1 from this activity. The program provides technical assistance but does not monitor the beekeeping activities. Vegetation preservation of the areas have been protected by PES, i.e. contracted technicians conduct surveys on site and through geoprocessing. The program has established conservation priorities, making larger payments following the order: cloud forests, dry forest and forest impacted by livestock. The initial proposal was that the project could be financed by downstream agricultural producers who benefit from the good water quality, resulting from forest conservation in higher parts, but they were not willing to pay (Asquitha et al. 2008).

\section{RESULTS AND DISCUSSION}

\section{Amounts paid to the populations involved and the opportunity costs}

Of the five studied cases, the PES developed in Tarangire National Park, Maya Biosphere Reserve and Wolong National Nature Reserve were clearly more successful. The first positive point in these three initiatives is related to payment amount and opportunity cost. If the offered amount is low and the opportunity cost is high, the abandonment of activities practiced by the populations involved is not encouraged, which could be harmful to environmental services (ES) maintenance (Wunder 2008, Engel et al. 2008). Thus, the PES tend not to be efficient in situations in which the landowners, most valued by the real estate market, are not attracted by the amounts offered, as was the case of the Nairobi National Park. The PES programmes that offer low, undifferentiated and non-targeted payments are likely to fail (Engel et al. 2008).

In the Ambóro National Park PES, the forest cover maintenance is linked to beekeeping success, but not all participants obtained success. In this way, the beehives sale or abandonment may possibly promote the return of invasion and deforestation threats, and consequently conflict continuity. Although some owners opt for fruit tree seedlings or wire fences, it can be understood that PES implementation through incentives that are not financial by socioeconomic practices, can present problems especially when the activities are not part of the local culture, and so require a learning curve. Another PES negative point is the search for efficient resource investment, that may favor some ecologically more interesting areas to the detriment of others. Chan et al. (2017) reported differentiate payments that may have negative consequences, such as the creation of barriers to participation. For example, in the Ambóro Natiional Park case, the properties located in the higher parts (cloud forests) are more valued in payment than those in dry forests, which in turn are more valued than the forests impacted by livestock.

In the Wolong Reserve and Maya Biosphere Reserve, the payment amount and opportunity cost were satisfactory. In the first program, the populations abandoned firewood use and begun to consume electricity. Thus, within seven years of monitoring, it was found that PES was more efficient than reserve establishment in the reduction of deforestation. In the Maya Biosphere Reserve, the payment amount and opportunity cost were enough for the communities to abandon the uncontrolled subsistence hunting on M. ocellata bird, and it was more advantageous to work on the activities established by the Pavo project PES.

Specifically, the amounts paid in Tarangire were equal for all tribes, and so the opportunity cost was also equal. However, it should be noted that in this program the number of ES suppliers is small and homogeneous, unlike Nairobi, since all the population use the Sirimanjaro plains to graze livestock communally without fences separating the properties. This benefits wildlife during dry season, and consequently the tourism. Another advantage is the existence of a tourism 
market dependent on ES, and the positive relation of Tarangire tribes with this activity, which does not exist in Nairobi.

\section{Valorisation of knowledge, social organisation and experience of the communities involved in new economic arrangements}

In Tarangire and Maya Biosphere Reserve PES, the positive results are a consequence of various factors, such as recognition of the communities' knowledge on ES in question, its political/social organisation and the communities' experience in working with new financial arrangements, which is fundamental to PES effectiveness (Chan et al. 2017). In the Maya Biosphere Reserve, the population participation in forest concession is a long-standing practice, and in the Tarangire National Park the tourism activities have been incorporated into their daily practices, contributing towards effective participation in negotiations, contract and ES supply.

Another positive factor that contributed towards the success of both PES initiatives is a promising market in Maya Biosphere Reserve for M. ocellata sport hunting, and tourism and sport hunting in the Tarangire National Park. It is important to emphasise that these markets are favored by ESs, maintained by the knowledge of the populations involved in PAs, due to the existence of buyers that are willing to pay.

\section{A financial view of the future of PES}

A very relevant issue about PES is about its capacity to continue if financial resources are withdrawn (Wunder 2008). This problem is fundamental to PES continuity, since environmental services do not follow laws, rules and schedules, but continue to exist due to dependence on them. In this sense, the participation of the funding source is very important for PES maintenance. Chan et al. (2017) reported that withdrawing financial incentives, after they have been introduced, may have a negative effect, i.e., ES suppliers may stop contributing because they believe they are entitled to receive compensation or because the agreement has not been fulfilled. Thus, the end of PES or non-payment of an agreed amount may increase the pressure on the ESs to a greater condition than it was before the payments were started.

Analysing the five PESs, different realities were found: (a) the resources coming from the
Pavo project, conservation of $M$. ocellata, funds all PES of Maya Biosphere Reserve, (b) the tourism operators who profit from the presence of wildlife on the Sirimanjiro plain in Tarangire National Park, finance part of the PES, but the wage payments are subsidised by the Wildlife Conservation Society, (c) The Wolong Reserve PES is fully funded by the Chinese Government through NFCP, (d) in Ambóro National Park, the municipality of Pampa Grande finance the PES, together with US Fish and Wildlife Service, and (e) in Nairobi National Park funding is carried out by the Wildlife Conservation Society.

In terms of funding, it was understood that the Pavo project PES, developed at Maya Biosphere Reserve, is the best perspective, since it does not depend on external funding, and is therefore less subject to global economic instability and local political changes. Financially, it depends on the success of the Pavo project and the continuity of the market for hunting $M$. ocellata.

The PES developed in Tarangire National Park (b) follows the same direction as that applied in the Maya Biosphere Reserve, where the tour operators are the main beneficiaries from the local fauna that they finance. However, monitoring, which is an important part of the PES, is funded by the Wildlife Conservation Society, an external source of subject to global market instability. Thus, the possible withdrawal of its resources could contribute to PES failure, and may lead to increased pressure on humid plains and local fauna, thus jeopardising tourism, its main financier.

The Wolong Reserve reality (c) can be considered positive in three respects: the China's economic momentum which favors long-term financing of the project, the worldwide appeal for giant panda conservation and the existence of a promising tourist market, mainly due to the presence of these species. However, the fact that the government is the only funder could compromise PES effectiveness long term, since government-funded programs are subject to political mandated durations, which is less likely to occur in user-funded PES programmes (Engel et al. 2008).

In Ambóro National Park (d) the initial proposal was for financing to be carried out by the agricultural producers, downstream of the river, they being the major beneficiaries of the forests conservation. For Pagiola and Platais (2007), PES programmes in which users are the financers, tend to be more efficient because they 
have more information about the service value, and are directly involved and observe the delivery of the services, and a possibility of renegotiating the contract if necessary. However, there was no such disposal from rural producers, thus it is financed by the Pampa Grande municipality and US Fish and Wildlife Service. As in Wolong Reserve, political changes could remove the municipality from the project and leave only an external funding source, thus reducing the possibilities of its continuity.

In the Nairobi National Park (e), the PES leasing program on Athi-kputiei plains is fully funded by the Wildlife Conservation Society, and thus may suffer from possible changes in world economy, similar to other initiatives dependant on external resources. The existence of only one financier is another negative factor for consideration, because the program may end if the investment is withdrawn.

\section{The relationship between PES programmes and other strategies for conservation of PAs and "parks versus people" conflicts: PAs and ICDPs}

The PES are market instruments while PAs are command and control instruments, established by public policies in order to conserve biodiversity and environmental services. Under the environmental economics view, PES are considered more efficient, since command and control regulation tend to prescribe the same level of activity for all ES suppliers, while marketbased instruments are more flexible (Engel et al. 2008). The Wolong Reserve corroborates with the study, as in seven years of monitoring it was found that PES was more efficient than command and control policies in generating

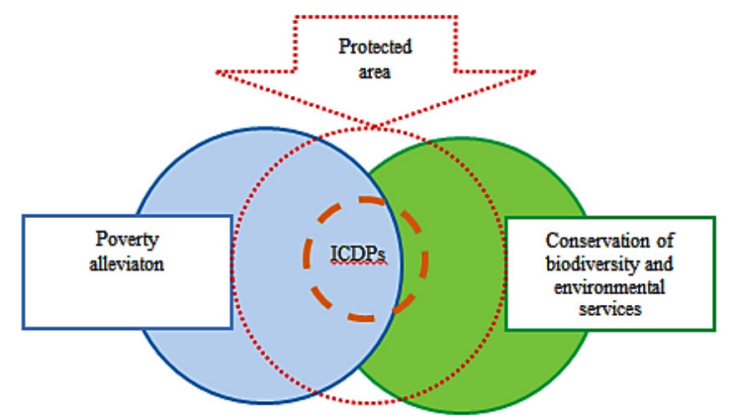

an increase in forest cover (Tuanmu et al. 2016). The African parks analysed in this study are located in Savannas and are not able to protect the flow of migratory fauna solely within their boundaries (Nelson et al. 2010, Leeuw et al. 2014). Thus the PES of the two parks searched for complementary to cover the gap. However, in the initiative developed in Tarangire National Park, it was attempted to involve the populations inhabiting the park surroundings into conservation practices in order to generate income and social inclusion, and thus contribute to the poverty alleviation and conflicts smoothing. The more flexible PA categories, in relation to the biological resources use (categories III, IV, V and VI of IUCN) may fail to maintain forest cover and to conserve endangered species (Françoso et al. 2015). Thus, the PES programmes can act in a complementary way by filling the gaps left by these PAs, as observed in PES of Maya Biosphere Reserve.

The ICDPs have been implemented to alleviate the poverty of populations affected by the restrictive PAs establishment (categories Ia, Ib and II of IUCN) and to help conservation by reducing both conflicts and pressure on biological resources in interior and buffer zones (Alpert 1996, Bauch 2014). However, experiences in Asia, South America and Africa have shown that ICDPs did not fully achieve their stated goals. When biodiversity conservation and human well-being occurred, they were dissociated or lacked equity in resource distribution among the members of the populations benefitting by the funding resources (Alpert 1996, Kellert et al. 2000) (Figure 2). For example, in Malaysia, in the Ranomafana National Park, new sources of income created by ICDP were incorporated into traditional activities, initially considered

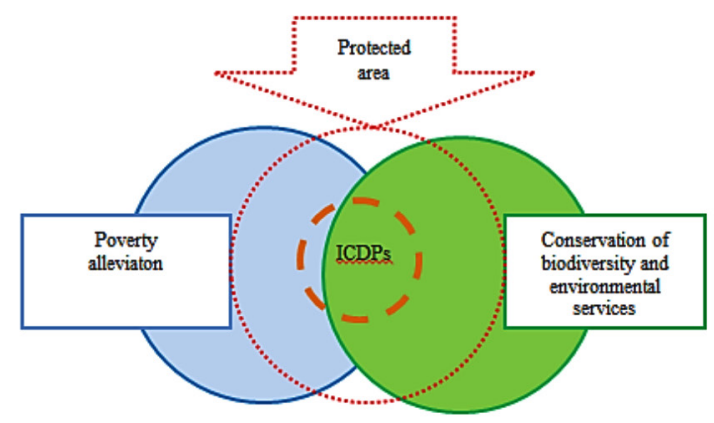

Figure 2 Integrated Conservation and Development Project (ICDP) scheme applied to Protected Area (PA) demonstrating the disassociation between poverty alleviation and conservation of biodiversity and environmental services 
harmful to PAs, instead of being replaced (Peters 1998). In five ICDPs studied in African continent, revenue from tourism was included into two initiatives favored by good quality roads and easy megafauna visualisation (Alpert 1996). In the national forest of Tapajós, in Brazilian Amazon, an ICDP that aimed to reduce cattle herds in the vicinity of the PA, to reduce deforestation, have had results only in herd decline (Bauch 2014).

These examples show that generating income alone is not sufficient to maintain ESs. It is fundamental to have conditions to deliver the ESs, as required in PES (Wunder 2015). In the ICDP analysis, projects were created with the hope that the activities or behaviors impacting the ES would cease only with the creation of new income sources, without any counterpart, which does not occur in PES projects, since they include the counterpart requirement registered in contract (Engel et al. 2008).

\section{CONGLUSIONS}

Although mitigating the "parks versus people" conflict is not the main objective of the PES initiatives developed in PAs, the results of this study have indicated that its a great possibility, when associated with such areas. However, further research is needed for a more detailed analysis. It is also concluded that the use of PES developed in PAs should not divert the focus from ES conservation towards poverty alleviation of populations affected by conservationist restrictions, nor should the opposite be done. It is necessary to search for the integration of populations involved in conflicts with ESs conservation through PESs. In this sense, it is also fundamental to use other biodiversity preservation strategies that may guarantee and encourage the participation of populations involved in the PA management processes, from diagnoses to decision-making stages, thus considering the people's participation as a premise.

\section{REFERENCES}

Adams WM \& Hutton J. 2007. People, parks and poverty: political ecology and biodiversity conservation. Conservation and Society 5: 147-183. doi:http:/ /www.conservationandsociety.org/text asp?2007/5/2/147/49228.

AlPert P. 1996. Integrated conservation and development projects. BioScience 46: 845-855. doi: https://doi. org/10.2307/1312970.
Asquith NM, Vargas MT \& Wunder S. 2008. Selling two environmental services: in-kind payments for bird habitat and watershed protection in Los Negros, Bolivia. EcologicalEconomics 65: 675-684. doi: https:// doi.org/10.1016/j.ecolecon.2007.12.014.

Bauch SC, SillLS EO \& PatTanayak SK. 2014. Have we managed to integrate conservation and development? ICDP impacts in the Brazilian Amazon. World Development 64: 135-148. doi: https://doi.org/10.1016/j. worlddev.2014.03.009.

Baur EH, Mcnab RB, Williams Jr LE et al. 2012. Multiple forest use through commercial sport hunting: lessons from a community-based model from the Petén, Guatemala. Forest Ecology and Management 268: 112-120. doi: 10.1016/j.foreco.2011.06.005.

Brockington D, Igoe J \& Schmidt-Soltau K. 2006. Conservation, human rights and poverty reduction. Conservation Biology 20: 250-252. doi: https://doi. org/10.1111/j.1523-1739.2006.00335.x.

BRoCKINGTON D. 2002. Fortress Conservation: The Preservation of the Mkomazi Game Reserve, Tanzania. Indiana University Press, Bloomington. doi: 10.2307/3097688.

Chan KM, Anderson E \& Chapman M et al. 2017. Payments for ecosystem services: Rife with problems and potential-for transformation towards sustainability. Ecological Economics 140: 110-122. doi: https://doi. org/10.1016/j.ecolecon.2017.04.029.

Clements T \& Milner-Gulland EJ. 2015. Impact of payments for environmental services and protected areas on local livelihoods and forest conservation in northern Cambodia. Conservation Biology 29: 78-87. doi: 10.1111/cobi.12423.

De Pource K, Thomas E \& Arts B et AL. 2017. Understanding and resolving conflict between local communities and conservation authorities in Colombia. World Development 93: 125-135. doi: https://doi. org/10.1016/j.worlddev.2016.12.026.

Engel S, Pagiola S \& Wunder S. 2008. Designing payments for environmental services in theory and practice: an overview of the issues. Ecological economics 65: 663-674. doi: https://doi.org/10.1016/j. ecolecon.2008.03.011.

Fisher B, Kulindwa K \& Mwanyoka I et al. 2010. Common pool resource management and PES: lessons and constraints for water PES in Tanzania. Ecological Economics 69: 1253-1261. doi: https://doi.org/ 10.1016/j.ecolecon.2009.11.008.

Françoso RD, Brandão R, Nogueira CG et al. 2015. Habitat loss and the effectiveness of protected areas in the Cerrado Biodiversity Hotspot. Natureza $\mathcal{E}^{\circ}$ Conservação 13: 35-40. doi: https://doi.org/10. 1016/j.ncon.2015.04.001.

He G, Chen X, Beaer S, Colunga M et al. 2009. Spatial and temporal patterns of fuelwood collection in Wolong Nature Reserve: implications for panda conservation. Landscape and Urban Planning 92: 1-9. doi: https:// doi.org/10.1016/j.landurbplan.2009.01.010.

IUCN (INTERNATIONAL UNION FOR CONSERVATION OF NATURE AND Natural Resources). 1994. Guidelines for Protected Area Management Categories. IUCN, Gland/Cambridge.

Kellert SR, Mehta JN, Ebiin SA \& Lichtenfeld LL. 2000. Community natural resource management: promise, rhetoric and reality. Society $\mathcal{E}$ Natural Resources 13: 705-715. doi: https://doi org/10.1080/ 089419200750035575 . 
Leeuw JM, Said MY, Kifugo S, OgutU JO, Osano P \& De LeEuw J. 2014. Spatial variation in the willingness to accept payments for conservation of a migratory wildlife corridor in the Athi-Kaputiei Plains, Kenya. Ecosystem Services 8: 16-24. doi: https://doi. org/10.1016/j.ecoser.2014.01.003.

Liu J, Linderman M, Ouyang Z, An L, Yang J \& Zhang H. 2001. Ecological degradation in protected areas: the case of Wolong Nature Reserve for giant pandas. Science 292: 98-101. doi: 10.1126/science.1058104.

Mcshane T, Hirsch PD, Trung TC et AL. 2011. Hard choices: making trade-offs between biodiversity conservation and human well-being. Biological Conservation 144: 966-972. doi: https://doi.org/10.1016/j. biocon.2010.04.038.

Naughton-Treves L, Holland, MB \& Brandon K. 2005. The role of protected areas in conserving biodiversity and sustaining local livelihoods. Annual Review of Environment and Resources 30: 219-252. doi: https:// doi.org/10.1146/annurev.energy.30.050504.164507.

Nelson F, Foley C, Foley LS et al. 2010. Payments for ecosystem services as a framework for communitybased conservation in northern Tanzania. Conservation Biology 24: 78-85. Doi: https://doi. org/10.1111/j.1523-1739.2009.01393.x.

Pagiola S \& Platais G. 2007. Payments for Environmental Services: From Theory to Practice. World Bank, Washington. doi: http://hdl.handle.net/10919/65833.
Pascual U, Phelps J, Garmendia E et al. 2014. Social equity matters in payments for ecosystem services. Bioscience 64: 1027-1036. doi: https://doi.org/10.1093/biosci/ biu146.

Peters J. 1998. Transforming the integrated conservation and development project (ICDP) approach: observations from the Ranomafana National Park Project, Madagascar. Journal of Agricultural and EnvironmentalEthics 11: 17-47. doi: https://doi.org/ 10.1023/A:1007796628731.

SChaller GB. 1985. Giant pandas of Wolong. University of Chicago Press, Chicago. doi: https://doi. org/10.1086/414647.

Simmel G. 1986. The sociology of conflict. American Journal of Sociology 9: 490-525.

Tuanmu MN, Vina A, Yang W, Chen X, Shortridge AM \& Liu J. 2016. Effects of payments for ecosystem services on wildlife habitat recovery. Conservation Biology 30: 827-835. doi: https://doi.org/10.1111/cobi.12669

WUnder S. 2008. Payments for environmental services and the poor: concepts and preliminary evidence. Environment and development economics 13: 279-297. doi: https://doi.org/10.1017/S1355770X08004282.

WUNDER S. 2015. Revisiting the concept of payments for environmental services. Ecological Economics 117: 234-243. doi: https://doi.org/10.1016/j. ecolecon.2014.08.016. 